\title{
Relationship between the Types of Malocclusion and the Localization of Headaches in Adults
}

\author{
Natalya M. Didenko ${ }^{1}, \mathrm{PhD}$; Arcady Ya. Vyazmin ${ }^{1}, \mathrm{PhD}, \mathrm{ScD}$; Evgeniy V. Mokrenko ${ }^{1}, \mathrm{PhD}$; \\ Vladimir V. Gazinskiy', PhD; Maria I. Suslikova ${ }^{1}, \mathrm{PhD}$; Marina A. Darenskaya ${ }^{2 *}, \mathrm{PhD}, \mathrm{ScD}$; \\ Victoria B. Andreeva ${ }^{1}$; Daniil Aksnes ${ }^{1}$; Marina I. Gubina ${ }^{1}, \mathrm{PhD}$ \\ ${ }^{I}$ Irkutsk State Medical University \\ ${ }^{2}$ Scientific Centre for Family Health and Human Reproduction Problems \\ Irkutsk, the Russian Federation
}

\begin{abstract}
The aim of this study was to investigate the manifestations of headaches in adult patients with types of malocclusion and occlusion deformities.

Methods and Results: The study was conducted in 171 adult patients (43 men and 128 women) with malocclusion and occlusion deformities at the age of 18 to 62 years old, who were examined in the orthopedic dentistry clinic. The nature of the dentition closing was studied directly in the patient's oral cavity, and with the help of the "Gnatomat" universal articulator on diagnostic plaster models of the jaws. The occlusal relationships of the teeth were analyzed in the position of the central, anterior, lateral and dynamic occlusions. The biomechanics of the lower jaw movements were studied in 3 mutually perpendicular directions. The detected anomalies and deformities of the occlusion were grouped as sagittal, transversal and vertical. Each group was diagnosed as independent forms of malocclusion, and combined with other anomalies and deformities of the dentoalveolar system. All the subjects were asked to answer the questions of a questionnaire specially developed for our study. The unified questionnaire was developed based on a modified rating questionnaire and the determination of the life disorders index in neck pain. The questionnaire includes blocks of questions aimed at identifying the localization of the headache in the temporal, parietal (in one or both) regions, occipital, frontal regions and in the longitudinal seam region.

We identified complaints of patients with pain in adjacent regions of the head. Of the 171 examined adult patients with malocclusion and occlusion deformities, 99 (57.9\%) complained of headaches. The presence of a headache in the parietal region of the head was associated most often with sagittal and transversal malocclusions. The presence of a headache in the temporal part of the head was associated often with vertical malocclusion The results of correlation analysis showed that pain in 2 regions of the head was associated with malocclusion: the temporal region $\left(r_{\mathrm{b}}=0.9892, P=0.0013\right)$ and parietal region $\left(r_{\mathrm{b}}=0.9712, P=0.0058\right)$. Other regions were not statistically significantly associated with malocclusion.

Conclusion: There is a certain relationship between the types of malocclusion, occlusion deformities and localization of headaches in adults. Headaches in the parietal and temporal regions of the head are associated with malocclusion and occlusion deformities more often. The obtained data can serve as a basis for the development of recommendations for appropriate corrective measures in orthodontic practice. (International Journal of Biomedicine. 2021;11(2):197-200.)
\end{abstract}

Key Words: malocclusion • occlusion deformities • headache

For citation: Didenko NM, Vyazmin AYa, Mokrenko EV, Gazinskiy VV, Suslikova MI, Darenskaya MA, Andreeva VB, Aksnes D, Gubina MI. Relationship between the Types of Malocclusion and the Localization of Headaches in Adults. International Journal of Biomedicine. 2021;11(2):197-200. doi:10.21103/Article11(2)_OA12

\section{Introduction}

The relationship between pathological conditions of the dentoalveolar system and disorders in the cranial and facial parts of the head is currently established. ${ }^{(1)}$ It has been found that minor changes in the relationship between teeth and jaws, combined with stress factors, lead to painful spasms of the masticatory muscles and, as a result, to headaches and facial pain. ${ }^{(2-6)}$ Painful dense formations, in the thickness of which there are regions of hypersensitivity, myofascial trigger points (MTPs), are found in the masticatory muscles of such patients. The term myofascial pain syndrome refers 
to sensitive, motor, and vegetative symptoms caused by MTPs. ${ }^{(7)}$ There is evidence that MTPs play a significant role in the pathogenesis of tension headaches. ${ }^{(8)}$ The mechanism by which musculofascial headaches occur is that the trigger point activates and sensitizes the neurons of the spinal cord posterior horns, leading to the reflection of pain in regions distant from the trigger point, according to the segments. The reflected pain is felt as a headache in the frontal, temporal, or parietal regions. These headaches are very common and make up the majority of outpatient visits of patients with complaints of headaches. ${ }^{(9)}$ However, there is still no information on the relationship between the types of malocclusion and the occurrence of headaches.

The aim of this study was to investigate the manifestations of headaches in adult patients with types of malocclusion and occlusion deformities.

\section{Material and Methods}

The study was conducted in 171 adult patients (43 men and 128 women) with malocclusion and occlusion deformities at the age of 18 to 62 years old, who were examined in the orthopedic dentistry clinic.

Each patient received sufficient information about the aim, methods, expected benefits, potential risks, and inconveniences that may arise from participation in the study, as well as other significant aspects of the study, before being included in it. Patients had the right to withdraw from the study at any time or withdraw their consent without giving reasons. Voluntary informed consent to participate in the study was issued only after the potential participants had read the information provided to them. After signing the voluntary informed consent, a medical examination was carried out, including an oral examination and a diagnosis provided for in the plan of our study.

The nature of the dentition closing was studied directly in the patient's oral cavity, and with the help of the "Gnatomat" universal articulator on diagnostic plaster models of the jaws. The occlusal relationships of the teeth were analyzed in the position of the central, anterior, lateral and dynamic occlusions. The biomechanics of the lower jaw movements were studied in 3 mutually perpendicular directions. Therefore, the detected anomalies and deformities of the occlusion were grouped as sagittal, transversal and vertical. Each group was diagnosed as independent forms of malocclusion, and combined with other anomalies and deformities of the dentoalveolar system.

All the subjects were asked to answer the questions of a questionnaire specially developed for our study. The unified questionnaire was developed based on a modified rating questionnaire and the determination of the life disorders index in neck pain. ${ }^{(10)}$ The questionnaire includes blocks of questions aimed at identifying the localization of the headache in the temporal, parietal (in one or both) regions, occipital, frontal regions and in the longitudinal seam region.

Statistical analysis was performed using the Statistica 6.0 software package (Stat-Soft Inc., USA). The frequencies of categorical variables were compared using Pearson's chisquared test or Fisher's exact test, when appropriate. The biserial correlation coefficient $\left(r_{\mathrm{b}}\right)$ was calculated to measure the strength and direction of the linear relationship between two variables. A value of $P<0.05$ was considered significant.

\section{Results and Discussion}

We identified complaints of patients with pain in adjacent regions of the head. Of the 171 examined adult patients with malocclusion and occlusion deformities, 99 $(57.9 \%)$ complained of headaches.

There were no differences in the frequency of occurrence of the type of malocclusion or occlusion deformities in patients with headaches (Table 1) At the same time, the presence of a headache in the parietal region of the head was associated most often with sagittal malocclusion in comparison with temporal $(P=0.0168)$, occipital $(P=0.0002)$, and frontal regions $(P<0.0001)$. The pain in the parietal region associated with sagittal anomalies was localized more often from 2 sides than from 1 side $(P=0.0004)$. Also, the presence of a headache in the parietal region of the head was associated often with transversal malocclusion, in comparison with occipital $(P<0.0001)$, longitudinal seam $(P=0.0003)$ and frontal $(P<0.0001)$ regions. The pain in the parietal region associated with transversal anomalies was localized more often from 1 side than from 2 sides $(P=0.0004)$. The presence of a headache in the temporal part of the head was associated often with vertical malocclusion, in comparison with the occipital $(P<0.0001)$, longitudinal seam $(P=0.0006)$ and frontal $(P=0.0006)$ regions (Table 1$)$.

\section{Table 1.}

The frequency of headaches in patients with malocclusion and occlusion deformities

\begin{tabular}{|l|c|c|c|}
\hline \multirow{2}{*}{ Head regions } & \multicolumn{3}{|c|}{ Malocclusion and occlusion deformities } \\
& \multicolumn{3}{|c|}{ (\%) } \\
\cline { 2 - 4 } & $\begin{array}{c}\text { Sagittal } \\
36(36.4 \%)\end{array}$ & $\begin{array}{c}\text { Transversal } \\
37(37.4 \%)\end{array}$ & $\begin{array}{c}\text { Vertical } \\
26(26.3 \%)\end{array}$ \\
\hline Temporal region & $10(27.8 \%)$ & $11(29.7 \%)$ & $14(53.8 \%)^{*}$ \\
\hline Parietal region & $20(55.6 \%)^{*}$ & $19(51.4 \%)^{*}$ & $8(30.8 \%)$ \\
\hline Occipital region & $5(13.9 \%)$ & $1(2.7 \%)$ & 0 \\
\hline Longitudinal seam & 0 & $4(10.8 \%)$ & $2(7.7 \%)$ \\
\hline Frontal region & $1(2.8 \%)$ & $2(5.4 \%)$ & $2(7.7 \%)$ \\
\hline
\end{tabular}

* - statistically significant differences with other indicators

As a result of correlation analysis, we obtained correlation coefficients $r_{\mathrm{b}}$ that characterize the measure of a linear relationship between the dependence of pain in a certain head region on the type of malocclusion or occlusion deformities (Table 2). It was found that pain in 2 regions of the head was associated with malocclusion: the temporal region $\left(r_{\mathrm{b}}=0.9892, P=0.0013\right)$ and parietal region $\left(r_{\mathrm{b}}=0.9712\right.$, $P=0.0058)$. Other regions were not statistically significantly associated with malocclusion. 
Table 2.

Dependence of pain localization in certain head regions on the malocclusion type

\begin{tabular}{|c|c|c|}
\hline Head region & $P$-value & $r_{\mathrm{b}}$ \\
\hline Temporal region & $0.0013 *$ & 0.9892 \\
\hline Parietal region & $0.0058 *$ & 0.9712 \\
\hline Occipital region & 0.2989 & 0.5861 \\
\hline Longitudinal seam & 0.7985 & -0.1589 \\
\hline Frontal region & 0.1027 & -0.8018 \\
\hline
\end{tabular}

* - statistically significant correlations

Tension headache, especially combined with dentoalveolar anomalies, is currently insufficiently studied, and therefore there is still no optimal treatment for it. Headaches of this type belong to comorbid pathologies, negatively affect the patient's quality of life and need a more detailed examination by various specialists. ${ }^{(11-13)}$ In our study, $57.9 \%$ of patients with malocclusion and occlusion deformities suffered from headaches. Currently, there are 2 main pathophysiological mechanisms of the mutual influence of headaches and malocclusion and occlusion deformities. ${ }^{(14)}$ This is sensitization of nociceptive structures and a decrease in the activity of antinociceptive systems of the central nervous system. ${ }^{(15)}$ Central sensitization is considered one of the main mechanisms for maintaining chronic pain; if it is present, dependence on peripheral triggering factors is lost, and resistance to therapy develops. ${ }^{(16-18)}$ This assumption is consistent with the data of D. Goncales, which was confirmed by clinical data when examining 300 patients. ${ }^{(19)}$ Impaired antinociceptive functions can also be the cause of the relationship between headaches and malocclusion and occlusion deformities. ${ }^{(13)}$ Soreness and hypertrophy of the masticatory muscles are likely due to central sensitization and impaired pain control. This hypothesis is supported by the data of a number of studies, which showed that patients with malocclusion and occlusion deformities have decreased pain thresholds from pressure contralaterally and ipsilateral with respect to the pain side, not only in the masticatory muscles themselves, but also in distant muscle groups. ${ }^{(20)}$ In this case, even normal proprioceptive impulses from the masticatory muscles are perceived as painful, and the tension in them is a consequence of the activation of the motor cortex during central sensitization. ${ }^{(21)}$

Currently, there are various tactics of pain syndrome treatment to reduce pain afferentation. ${ }^{(22)}$ We identified a more detailed localization of pain associated with malocclusion and occlusion deformities. These areas were the temporal and parietal areas, which were most often associated with sagittal, transversal and vertical occlusion types of deformities. The identified changes require further research on the relationship between headaches and malocclusion and occlusion deformities. It is also important to identify possible new therapeutic approaches, in particular in the presence of complex cases.
In conclusion, there is a certain relationship between the types of malocclusion, occlusion deformities and localization of headaches in adults. Headaches in the parietal and temporal regions of the head are associated with malocclusion and occlusion deformities more often. The obtained data can serve as a basis for the development of recommendations for appropriate corrective measures in orthodontic practice.

\section{Competing Interests}

The authors declare that they have no competing interests.

\section{References}

1. Stephanidi AV. [The value of temporomandibular joint muscle dysfunction in the development of cranioalgia syndrome]. Bulletin of the East Siberian Scientific Center of the Siberian Branch of the Russian Academy of Medical Sciences. 2003;5:89-94. [Article in Russian].

2. Bugrovetskaya EA, Gvozdeva SV, Didenko A, Solovykh OG, Bugrovetskaya OG. [Postural balance and occlusion of teeth. The role of occlusion disorders in the occurrence of postural imbalance in neurosomatic diseases]. Manual therapy. 2008;2(30):40-48. [Article in Russian].

3. Darenskaya MA, Grebenkina LA, Mokrenko EV, Shabanov PD, Suslikova MI, Mokrenko ME, Sinyova YuO, Goncharov IS, Gubina MI, Kostritsky IYu, Bulnaeva AF, Proskurnina EV, Kolesnikova LI, Kolesnikov SI. Lipid Peroxidation Activity and Immune Response in Modeling Inflammatory and Degenerative Damage to the Periodontium of Rats. International Journal of Biomedicine. 2019;9(2):159162. doi: 10.21103/Article9(2)_OA16

4. Darenskaya MA, Kolesnikova LR, Rychkova LV, Pogodina AV, Grebenkina LA, Kolesnikova LI, Kolesnikov SI. Lipid peroxidation-antioxidant defense system functional state in adolescents with arterial hypertension and dental caries comorbidity. Free Radical Biology \& Medicine. 2020;159(S1):S88-S89. DOI: 10.1016/j. freeradbiomed.2020.10.229

5. Kolesnikova LR, Darenskaya MA, Kolesnikova LI, Grebenkina LA, Korytov LI, Batoroev YK, Belinskaya EI, Mikhalevich IM, Kolesnikov SI. Morphofunctional State of the Periodontal Tissues in Humans and Rats with Arterial Hypertension. Bull Exp Biol Med. 2020 Oct;169(6):831-835. doi: 10.1007/s10517-020-04990-8.

6. Darenskaya MA, Kolesnikova LR, Rychkova LV, Grebenkina LA, Semenova NV, Kolesnikov SI, Kolesnikova LI. Indicators of Lipid Peroxidation Reactions and State of Structural Tissues of the Dentition System in Wistar Rats under Various Stress Regimes. International Journal of Biomedicine. 2020;10(2):142-147. doi: 10.21103/Article10(2)_OA11

7. Travell JG, Simons DG. Myofascial pain and dysfunction: a guide to trigger points. Moscow: Medicine. 2005. [Book in Russian].

8. Vein AM, Voznesenskaya TG. [Headache]. Clinical Medicine. 1998;11:63-65. [Article in Russian].

*Corresponding author: Marina A. Darenskaya, PhD, ScD. Scientific Centre for Family Health and Human Reproduction Problems, Irkutsk, the Russian Federation. E-mail: marina darenskaya@inbox.ru 
9. Fergusson LU, Gervin R. Treatment of myofascial pain: Clinical guidelines. Moscow: MEDpress-inform. 2008. 544. [Book in Russian].

10. Belova AN. Neurorehabilitation: A Guide for Doctors. 2nd ed., Rev. and add. Moscow: Antidor, 2002. 736. [Book in Russian].

11. Shroff B. Malocclusion as a Cause for Temporomandibular Disorders and Orthodontics as a Treatment. Oral Maxillofac Surg Clin North Am. 2018 Aug;30(3):299-302. doi: 10.1016/j. coms.2018.04.006.

12. Kolesnikova LR, Darenskaya MA, Kolesnikova LI, Grebenkina LA, Korytov LI, Batoroev YK, Belinskaya EI, Mikhalevich IM, Kolesnikov SI. Changes in the Periodontium and Pulp in ISIAH Rats Caused by Stress Exposures in Different Modes. Bull Exp Biol Med. 2019 Apr;166(6):722725. doi: 10.1007/s10517-019-04426-y.

13. Zenkevich AS, Filatova EG, Latysheva NV. [Migraine and temporomandibular joint dysfunction: mechanisms of comorbidity]. Zh Nevrol Psikhiatr Im S S Korsakova. 2015;115(10):33-38. Russian. doi: 10.17116/ jnevro201511510133-38.

14. Sonnesen L, Bakke M, Solow B. Malocclusion traits and symptoms and signs of temporomandibular disorders in children with severe malocclusion. Eur J Orthod. 1998 Oct;20(5):543-59. doi: 10.1093/ejo/20.5.543.

15. Al-Moraissi EA, Perez D, Ellis E 3rd. Do patients with malocclusion have a higher prevalence of temporomandibular disorders than controls both before and after orthognathic surgery? A systematic review and meta-analysis. J Craniomaxillofac Surg. 2017 Oct;45(10):1716-1723. doi: 10.1016/j.jcms.2017.07.015.

16. PoștaruC,PostnikovM,Uncuța,D.Evaluationofmasticatory muscles function in children with malocclusions associated with tension-type headache. 2020. Available from: http:// repository.usmf.md/bitstream/20.500.12710/14895/1/723
ABSTRACT BOOK_Culegere_de_rezumateABSTRACT BOOK_Culegere_de_rezumate.pd $\bar{d}$

17. Bairova TA, Kolesnikov SI, Kolesnikova LI, Pervushina OA, Darenskaya MA, Grebenkina LA. Lipid peroxidation and mitochondrial superoxide dismutase-2 gene in adolescents with essential hypertension. Bull Exp Biol Med. 2014 Dec;158(2):181-4. doi: 10.1007/s10517-014-2717-4.

18. Kolesnikova LR, Darenskaya MA, Kolesnikova LI, Grebenkina LA, Korytov LI, Batoroev YK, Belinskaya EI, Mikhalevich IM, Kolesnikov SI. Comparative Analysis of the Morphology of Dentition in Normotensive and Hypertensive Rats Exposed to Chronic Stress. Bull Exp Biol Med. 2019 May;167(1):7-10. doi: 10.1007/s10517-019-04449-5.

19. Gonçalves DA, Camparis CM, Speciali JG, Franco AL, Castanharo SM, Bigal ME. Temporomandibular disorders are differentially associated with headache diagnoses: a controlled study. Clin J Pain. 2011 Sep;27(7):611-5. doi: 10.1097/ AJP.0b013e31820e12f5.

20. Fernández-de-las-Peñas C, Galán-del-Río F, FernándezCarnero J, Pesquera J, Arendt-Nielsen L, Svensson P. Bilateral widespread mechanical pain sensitivity in women with myofascial temporomandibular disorder: evidence of impairment in central nociceptive processing. J Pain. 2009 Nov;10(11):1170-8. doi: 10.1016/j.jpain.2009.04.017.

21. Maixner W, Fillingim R, Sigurdsson A, Kincaid S, Silva S. Sensitivity of patients with painful temporomandibular disorders to experimentally evoked pain: evidence for altered temporal summation of pain. Pain. 1998 May;76(1-2):71-81. doi: 10.1016/s0304-3959(98)00028-1.

22. Bianchi J, Pinto ADS, Ignácio J, Obelenis Ryan DP, Gonçalves JR. Effect of temporomandibular joint articular disc repositioning on anterior open-bite malocclusion: An orthodontic-surgical approach. Am J Orthod Dentofacial Orthop. 2017 Dec;152(6):848-858. doi: 10.1016/j. ajodo.2016.09.032. 